\title{
The Future of the ACRL
}

\section{University Libraries Section}

$\mathrm{S}^{\mathrm{n}}$ INCE the functions of ACRL have substantially changed as a result of the reorganization of ALA, we cannot escape asking ourselves some soul-searching questions: How do we fit into this new picture? Can we simply carry on as if nothing had happened? In what respects will the removal of "types-of-activity" interests from ACRL affect our sectional programs and relationships?

When you ask questions of this sort, you are inevitably forced to reappraise past performances: What has the University Libraries Section been attempting to accomplish over the years, anyway? Have we set our stakes high enough? Are we an effective section? What are our objectives?

As we look over the record of the past eighteen years, since the founding of ACRL in 1940, we are driven to the conclusion that the University Libraries Section has accomplished too little. In fact, the section has essentially done nothing more than to provide about two or three hours of public paper-reading a year for the diversion or enlightenment of the members attending our ALA conferences. We have provided this entertainment each year, except during three war years (1943-45), when we were dormant, and in 1956 at Miami Beach, when ALA reorganization business crowded out program meetings. Most of the pa-

1 This article is based on an address by Mr. Muller presented at the ALA Midwinter Meeting, January 28,1958 .

Dr. Muller is Assistant Director, University of Michigan Library. He is currently Chairman of the University Libraries Section, ACRL. pers appeared in print later on. During recent years, program meetings have been slightly curtailed as a result of a ruling by ALA Council in 1952 that meetings at Midwinter must be restricted to business meetings.

The topics on our programs since 1940 have covered a wide range. Some were extremely general and formulated so as to enhance their audience appeal, as, for instance, the topic "The Educated Man and His Relationship to University Libraries in the Atomic Age" (1946), or "The Scholar's Paradise" (1954). A few topics related to resources and technical services, such as acquisition policy, microphotography, the cataloging code. A great many of the topics were familiar perennials that will probably continue to be with us for years to come, such as the problem of departmental libraries, the storage of little-used materials, the undergraduate versus the research demands upon library service, the place of rare books, archives, and manuscripts, accreditation, financing, and the possibilities of cooperation.

Most of us will not wish to give up our tradition of program meetings at conferences. What some will take issue with, however, is the position held by several of our more prominent members, that we should restrict our sectional activities to the presentation of interesting programs and let it go at that.

As the section of ACRL representing the most complex and most scholarly American libraries, we not only have many problems in common, but we also can promote the interests of our type of libraries through joint deliberation and 
joint action. What these interests are that call for a cooperative approach is not always easy to determine. Many of us become so wrapped up in the independent solution of our local problems that we tend to overlook opportunities for a joint attack on problems, which will save all of us time and energy in the long run.

Much cooperation can and does, of course, take place without the help of associational machinery in the same way that we negotiate treaties and pacts between countries outside the United Nations. But as long as we have an association, we must strengthen it to the point where it is ready to serve any of us as an effective medium of cooperative action in order to further the development of university libraries and university librarianship. Few will claim that our program meetings have in fact made a significant contribution in that direction, no matter how interesting, entertaining, enlightening, and timely they may have been.

At this point we should mention 1952. In that year, Chairman Ray Swank apparently also felt that program meetings were not enough and that we should be a little more ambitious and try to get a little more accomplished. So he appointed four committees: One on technical reports, one on in-service training, one on decentralization of cataloging, one on undergraduate and underclass libraries. It was a worthy effort, but it failed. Why the effort failed is difficult to determine. Perhaps the subject areas were not of sufficient interest to enough members; perhaps they were not amenable to committee management; perhaps the members of the committees were not properly motivated or not sufficiently energetic and resourceful. In any case, it seems important to keep this failure in mind and proceed very cautiously in any future effort at providing the section with a committee structure. It may be of interest, also, to point out that the subject matter of three of the four 1952 committees would now probably be ruled to be outside the legitimate province of ACRL. Hence the committees would probably be declared unconstitutional unless set up as joint committees with the Library Administration Division, Library Education Division, and Resources and Technical Services Division, respectively; and to establish such joint committees would require prior approval by the boards of directors concerned, all of which presents new complexities and formalities.

So much for a review of the past. Let me now report to you what has been done since the 1957 Kansas City Conference in preparation for the development of a stronger and more effective section. The first step was taken on August 19, 1957, when a one-page questionnaire was mailed to the slightly more than 2300 members of this section. The mailing was done from ALA Headquarters with the cooperation of our ACRL Executive Secretary, Richard Harwell. In the questionnaire we asked for opinions as to what the functions of the section should be, what activities we should undertake, what committees we should establish, if any, how we should relate ourselves to the Association of Research Libraries, and what topics we should cover during future program meetings. These questions were admittedly not easy questions to answer; they called for some fairly strenuous, sustained thinking, for which many librarians unfortunately find little time or opportunity during their typically very busy daily tours of duty. It was the sort of questionnaire that any of us is likely to place in a pending file, hoping that he will soon find time to compose a carefully considered reply.

A total of 39 replies, representing less than 2 per cent of the membership, were received by the October 15 deadline. In other words, 98 out of 100 members 
either did not have any opinions on the questions asked, or did not care enough to take the time to set them down on paper, or simply forgot to reply, or felt that they had nothing constructive to contribute. As one respondent put it: "The main reason for not answering your communication on the place and function of ULS in ACRL, aside from the usual ones of personal procrastination and perennial pressure, was simply not knowing what in the devil to say." Although some of the replies were most interesting as expressions of opinions, there was no assurance that the opinions expressed and their distribution were representative of how most of the membership felt about future programs and functions.

The second step consisted of the preparation of a summary of the major opinions expressed and questions raised in response to the August 19 questionnaire. This summary was mailed out on October 28 to the thirty-nine members who had responded to the August 19 questionnaire plus sixty-six head librarians of institutions offering the doctor's degree who had failed to respond to my earlier questionnaire, or a total of only 104 members. In the process of preparing this mailing list, it was discovered that the head librarians of nine important institutions granting the doctor's degree did not belong to the University Libraries Section: five of these nine were connected with ARL libraries. Of these five head librarians, four did not even belong to ALA, and one, although belonging to ALA, did not belong to ACRL. This is merely incidental information and not too alarming. It may, however, be taken as an early warning signal and may suggest that unless the University Libraries Section develops into a much more productive and effective group, it may occur to many others that membership in it is unimportant and can be dispensed with without loss.
The response to the second questionnaire was reasonably good, with forty of the sixty-six head librarians replying, in addition to further comments from those who had responded to the earlier questionnaire. The summary to be presented on the following pages is based primarily on the opinions expressed in these forty letters.

Before discussing the answers to specific questions in the questionnaire, it may be illuminating to present a few direct quotations from the letters received. These sixteen quotations were selected to show in a general way how widely divergent the attitudes and opinions of our members are. Let us begin at the negative end of the spectrum.

Quote No. 1, from one of our most distinguished libraries: "We have held a meeting .... attended by seven of the most professionally minded members of our library. I want to stress that this is not a hastily conceived reply to your very carefully stated problem but one which reflects our thinking on the problems raised by you. This group unanimously favors elimination of the University Libraries Section. . . . We believe that ACRL should be capable of arranging any programs that might be desirable at annual conferences, and appointing special committees on university problems whenever there is a clear need for a special forum for university libraries."

Quote No. 2, from a man who has had important committee assignments in ACRL: "As for giving any extended reply on the points enumerated in your memorandum, I wish only to say that I couldn't possibly be less interested in your questions. Like many others, I am so weary of talk and continuous talk of reorganization, etc., that I cannot discuss the subject in an unbiased way."

Quote No. 3, from a librarian who has played an important role in the development of ACRL: "I am not at all sure of the need for the section as things now stand. Certainly the section should not exist simply to provide more activity at the annual conference. ... With the reorganization, there appears to be even less opportunity for the 
section to give practical service. This letter is a little bitter. I truly appreciate the issues you have raised."

Quote No. 4, from the head of a state university library: "I feel that there is a great deal of amorphousness about the ACRL meetings. There seems to be a certain lack of direction in the programs that we've had and no connection from one program to the next. I would suggest further that the large group always stifles discussion; in these big groups there are always one or two people who have made themselves obnoxious over the years by always having something to say on every subject and saying it in such a way that there is a great deal of finality hanging about it. I would like to see ACRL have smaller groups."

Quote No. 5, from one of our most distinguished members: "I favor a relaxed attitude for the University Libraries Section. ... I think that one of the great values of a conference is an excuse for getting away from home with an opportunity to talk with acquaintances and colleagues who work on the same kind of thing on an informal basis, and the hope always of hearing something original or stimulating said. Consequently, I believe that a program which provides a few high quality performances provides the necessary excuse, offers possibility of stimulation and leaves plenty of time for corridor and bistro conversations."

Quote No. 6: "Social gatherings are nice but I couldn't justify the expenditure of travel money, either the University's or mine, to attend a professional gathering devoted only to social chit-chat. Or better that the shattered section be killed off, hard as it seems to exterminate moribund library organizations. We should make no pretense at doing things that need not be done at all, but I should view it as a pretty state of things when there is no serious work for us to do."

Quote No. 7: "Most of our members come to the meetings for the interesting programs and would not lose interest if the activities for a while were restricted to such programs, in whatever form they are presented."

Quote No. 8: "The University Libraries Section should have a minimum of organization; it should have joint meetings with scholarly organizations; it should work through the other organized groups."
Quote No. 9, from the librarian of a state university: "The only way any large organization can have strength is through continuing committees. I would therefore conclude that the University Libraries Section would have to have a strong committee structure to be effective."

Quote No. 10, from the head librarian of another state university: "As far as the need for committees is concerned I well remember the remark made by Larry Powell to the effect that when he took office, he found no committees in existence, and that he took no steps to establish any. In general, this is sound."

Quote No. 11, from an assistant director of a large library: "I have one strong reaction. Nothing has seemed more deadening than the attempt to hold sectional business meetings, particularly at Midwinter. The moment that an announcement is made that sections will have business meetings, there is a general exodus for the doors. I wish you could find some way to dispense with the open business meeting."

Quote No. 12, from a state university librarian: "The University Libraries Section should become more active and systematically attempt to identify the major problems facing university libraries and then organize a vigorous attack on these problems."

Quote No. 13, from the director of a large library: "I think the problems of this section are still what they have been since the ACRL with its several sections was formed. I also think it is best for you to ignore completely the recent attempt to reorganize the total library organization of ALA and affiliated bodies. It is going to be humanly and professionally impossible to relate to the socalled new divisions the problems of all types of libraries. There simply is no common denominator for all types of libraries which would make it possible to develop useful programs. Any programs that might be projected would be watered down to the point at which they would not be very useful. The province of the University Libraries Section is those university libraries that do work on the Ph.D. level. Of them there are about 100 . We should develop a vigorous program. We should strive to identify the problems of university libraries and do something about them."

Quote No. 14, from the head of another 
large university library: "I see little reason for the existence of the section if its only function continues to be the sponsorship of conference programs. The university libraries of the country are burdened with many problems which could be attacked by group action through our professional association. If the members of the section do not want to use the association for this purpose, I would favor abolishing the section and letting ACRL plan the conference programs. I would like to see an active section ... I have seen no evidence that the membership does not want to work."

Quote No. 15: "I believe that the section should be more active, that it should have a systematic program, and that it should identify and face up to the major problems of university librarianship. My feelings, however, on this point are not vague. They are positive and direct even though I cannot give good answers in terms of specifics. I hope that you and succeeding officers of the section will not be guided by a do-nothing philosophy. Should this happen throughout all the sections of ACRL, we might just as well fold up."

Quote No. 16, from another university: "I should like to say that if we do not keep this section active it will be likely to go out of existence, which I would very much regret to have happen."

So much for the quotations. It is evident that we are dealing here with a very wide spread of divergent views and that it will be difficult to develop a program that everyone will endorse. Let me now turn to the specific questions asked in the questionnaire addressed to head librarians of our major university libraries.

The first question asked was: Are we sufficiently active? In other words, should the University Libraries Section develop into a much more active organization, with a systematic program for study or discussion of some of the major problems facing university libraries, or should we primarily plan interesting programs, have no committees, and conduct no business meetings. The answers to this question distributed themselves as follows: 14 felt that we should become more active; 10 thought that we should restrict ourselves to program meetings at conferences; 3 said that we should have program meetings as well as active committees; 8 had no opinion; and 2 advocated that the section be abolished. It was obvious that the respondents lacked unanimity and that is was impossible to satisfy all. The answers were most useful, however, in identifying those members who favored a more active section, and several of them agreed to serve as members of a Steering Committee. The membership of this committee is as follows: William H. Carlson, Carl Hintz, David O. Kelley, A. Frederick Kuhlman, Frank Lundy, Ralph McComb, Flint Purdy, and Ray Swank. It is hoped that in due time a constructive program statement for future activities will emerge from the deliberations of this committee.

The committee will be concerned only with the University Libraries Section, and not with ACRL as a whole. Earlier, the ACRL Board of Directors established an ACRL Special Committee on Activities and Development (SCAD), headed by William H. Carlson, which has been studying the place of ACRL within the reorganized ALA and is to bring in recommendations for divisional action program. The two committees will be in close touch with each other as they reach the stage at which specific recommendations can be formulated.

The second question in the questionnaire pertained to our relationship to the Association of Research Libraries. Opinion as to the extent to which we should take cognizance of ARL was so widely divergent that it is impossible to present a complete picture of it in a summary. Roughly one-fourth believed that we should ignore ARL; about one-third believed that we should maintain fairly close liaison; another one-fourth expressed no opinion; the remainder expressed varying views, such as to let ARL handle joint projects and our section 
concern itself with internal problems of university libraries.

Equally confusing were the views revealed by librarians of ARL libraries as to the proper function of ARL. Some felt that ARL should return to its earlier function of an initimate discussion circle; others were convinced that its strength lay in its committee structure and action programs. It is not necessary to offer advice to ARL. Its officers are aware of the conflicting views, and its Advisory Committee has prepared an admirably concise report on the problems ARL will be concerned about. It seems highly desirable to maintain close liaison, so that we will eventually achieve a satisfactory division of labor rather than competition or duplication of effort in the field of university and research libraries.

ARL was founded at a time when ALA had no strong group representing university and research interests. It gained strength through an organizational structure and a budget that guaranteed continuity, and it gained prestige through its display of leadership as well as through its exclusiveness. With reference to its effect on ACRL, one of our members described the dilemma as follows: "It certainly has seemed that the existence of ARL has had a tendency to take initiative away from non-ARL members. Yet I can see that if the ARL did not initiate many of the projects it does, the university and college groups would be considerably impoverished." Another one wrote: "A great deal of the interest and activity of the potential leadership of the University Libraries Section is spent on ARL." A third one expressed a similar sentiment in stating that "the existence of ARL has weakened the University Libraries Section of ACRL." It seems obvious that we have a real problem here that can be solved only if we change the University Libraries Section of ACRL into a more responsible and more dynamic group. The University Li- braries Section may have to assume new functions that will make it more truly than before the spokesman for university library interests.

The only trouble is that our unwieldly University Libraries Section, which may be compared to a slumbering giant, is presently not set up to assume new duties. What it lacks primarily is continuity in its governing body, and without such continuity no action program can succeed. Our three officers (Chairman, Vice-Chairman, Secretary) are elected for a one-year term in contrast to the five-year, overlapping terms of the five members of the ARL Advisory Committee and the five-year term of the ARL Executive Secretary. In addition to our three officers, we also elect a so-called Director for a four-year term, whose only function has apparently been to attend the meetings of the ACRL Board of Directors. We have a situation, then, in which a new group of officers takes over at each annual conference. These officers usually have no official contact with the Director. An illusion of continuity is created by the tradition that makes the Vice-Chairman responsible for the planning of the program meeting at the annual conference; in practice, this tradition contributes little to the continuity of the governing personnel of the section as long as our activities involve nothing else but program meetings.

Fortunately, we enjoy complete freedom as to how to conduct our affairs. The ACRL Constitution does not prescribe what kind of organization ACRL sections must adopt. It was suggested that we might set up a governing committee of five, consisting of the Chairman, the Vice-Chairman, the past two chairmen and the Director. Some suggested a longer term of office for the elected officers with staggered terms. Several suggested that the Director should become more deeply involved in the activities of the section. It was also suggested that we might add the Secretary to 
the governing body. Another possibility is to continue our Steering Committee as advisory cabinet of appointed members. The majority of those who expressed an opinion on this matter agreed that steps should be taken to ensure greater continuity. The Steering Committee will include this topic on its agenda.

The final topic in my questionnaire concerned our ties with ACRL. Here the basic question was whether the ACRL Board of Directors should primarily serve as an instrument of the sections or whether it should continue to operate as a sort of superstructure, presuming to speak for all of us, yet having extremely weak links with the sections that make up ACRL. What we have had all these years is a fairly strong and active board, but relatively weak sections.

The Board of Directors consists of ACRL officers, ALA Councilors, and Directors-at-Large, all of them directly elected either by ACRL or ALA members. In addition, each section is represented by a Director, who is elected by ACRL for a four-year term upon nomination by the section, but whose involvement in section activities-through no fault of his own-has traditionally been nil.

It seems that our ACRL board should be set up in such a way that programs and projects approved by any section can be effectively presented at board meetings and implemented by board action; and it is most doubtful whether the best way to accomplish this objective is to set up a board on which neither the vicechairmen nor the chairmen of the sections have a vote. Quite in contrast to the divergence of opinion revealed on the other three topics covered in this report, the members who wrote on this point were in complete agreement that the proposed ACRL Constitution should be changed to provide for closer and more direct ties between the sections and the ACRL Board of Directors. This unanimity was most surprising in view of the absence of any dissenting vote at Kan- sas City when the proposed new constitution was first presented at an ACRL membership meeting.

An inquiry directed to the other five sections of ACRL revealed that their chairmen and vice-chairmen shared the conviction that the composition of the ACRL Board of Directors could be improved. They all agreed that ACRL would be strengthened if the sections were given more direct representation on the Board than Article V, Section 2 of the proposed constitution provided.

A study of the constitutions of other ALA Divisions revealed that there was no uniform pattern. In only two other divisions (PLD and YASD) were ALA councilors included as voting members of the board. There were two divisions (LED and RTSD) in which section chairmen were voting members of the board in contrast to their not being so included in ACRL. The final reading of the ACRL Constitution at the membership meeting in San Francisco in 1958 will give members an opportunity to decide what kind of organizational structure will be most appropriate for ACRL.

\section{SuMMARY}

It was pointed out that the work of the University Libraries Section has consisted almost exclusively of presenting interesting short programs at conferences. Although many members are satisfied with this level of attainment, there are a good many who are dissatisfied and feel strongly that we could and should accomplish more toward the solution of common problems and the improvement of university libraries. Before we can hope to become a more dynamic and more productive group, however, we shall first have to ensure greater continuity of organization than is true today, so that projects and programs can be carried forward from year to year until they are completed. Next we must try to coordinate our efforts with those of the Associa-

(Continued on page 202) 
music, physical education, physical sciences, and R.O.T.C. A summary of other general findings is as follows:

1. All staff members at Connors College have a clearer idea of opportunities available for the integration of the library with instruction.

2. Some instructors immediately increased requirement for work in the library. (As an example, instructors in R.O.T.C. for the first time required a research paper. Each freshman was assigned an important battle of some war in which the United States participated. $\mathrm{He}$ analyzed and gave documentary evidence of all major incidents of the battle. Special emphasis was given to the way the commanding officers carried out the nine basic "Articles of War" in directing the battle.) This was an interesting assignment.
3. Instructors came to the library to refresh their memory as to what books are available in their teaching area.

4. The librarian was made conscious of the opportunity she had for serving the program.

5 . Instructors were alerted to turn in requests for books to be ordered.

6. The librarian and some instructors worked out plans for the supervision of library reading for classes when instructors have to be absent from the college.

7. The administrators at Connors recognized the library as being the "central laboratory of the college" to be used as a definite part of the instruction program. Funds were provided for its growth insofar as current budget allows. The amount of funds for the purchase of books for the coming year was substantially increased.

\section{ACRL University Libraries Section}

(Continued from page 193)

tion of Research Libraries so as to avoid unnecessary duplication of effort and competition in the same general field. In view of the present unwieldiness of our membership and the complete absence of any organizational structure or articulation, the only way to make some headway was to appoint a Steering Committee, which met for the first time at the 1958 Midwinter Meeting to attempt to determine what activities we should undertake. All members are urged to funnel ideas to the members of this committee. The committee will work closely with the ACRL Special Committee on Activities and Developments, which has been studying the place of ACRL within the reorganized ALA and developing recommendations for an ACRL action program.

Next, it was pointed out that our links with the ACRL Board of Directors did not seem sufficiently strong and direct to enable us to carry forward any kind of active program which requires effective presentation to the board and active support by the board. It was, therefore, suggested that all members carefully study the provisions of the proposed ACRL Constitution, particularly Article V, Section 2, and transmit their ideas to the ACRL Board of Directors before it is too late, that is, before the Constitution will come up for final adoption at the San Francisco Conference in July of 1958.

The most difficult task before us and one which will require much ingenuity and resourcefulness on the part of each and every member, but particularly of the members of the Steering Committee is to determine what activities are appropriate for us to undertake as a group within ACRL and ALA to further the development of university libraries. It is not enough to feel in a vague sort of way that we should become more productive and more effective. We must get down to specifics and attempt to identify the major problems facing university libraries jointly and then determine what can be done about them through group effort. 